\title{
MÁRIO DE ANDRADE E LÉVI-STRAUSS: APRENDIZES DE UM CERTO BRASIL $^{1}$
}

\section{MÁRIO DE ANDRADE AND LÉVI-STRAUSS: APPRENDISES OF A CERTAIN BRAZIL}

\section{MÁRIO DE ANDRADE Y LÉVI-STRAUSS: APRENDICES DE UN CIERTO BRASIL}

\author{
Raquel Illescas Bueno ${ }^{2}$ \\ Universidade de São Paulo, São Paulo, Brasil
}

\begin{abstract}
Resumo: Nas décadas de 1920 e 1930, Mário de Andrade e Lévi-Strauss percorreram áreas bastante isoladas do território brasileiro. Foram, assim, viajantes e aprendizes de um certo Brasil profundo, que se propuseram a divulgar e preservar. Este trabalho identifica pontos de convergência entre os relatos de viagem reunidos em $O$ turista aprendiz (primeira publicação, 1976) e Tristes trópicos (1955) e compara aspectos da observação da cultura brasileira por cada um dos autores. O interesse pela arte popular e pelas culturas indígenas, com visada antropológica, são elementos basilares das duas obras. Ainda que os pontos de partida de seus autores fossem distintos, tanto geográfica como ideologicamente, a perspectiva antietnocêntrica é marcante nos dois trabalhos.
\end{abstract}

Palavras-chave: Literatura de viagem; O turista aprendiz; Tristes trópicos.

Abstract: In the 1920s and 1930s, Mário de Andrade and Lévi-Strauss traveled quite isolated areas of Brazil. They were travelers and apprentices of a certain deep Brazil, which they proposed to unveil and preserve. This work identifies points of convergence between the travel reports gathered in $O$ turista aprendiz (first published 1976) and Tristes trópicos (1955), comparing aspects of the Brazilian culture observed by each one of the authors. One of the core elements of the two books is the interest in popular art and in the cultures of indigenous, with an anthropological approach. Although the starting points of the authors were distinct both geographically and ideologically, the anti-ethnocentric perspective is remarkable in both works.

Key-words: Travel literature; $O$ turista aprendiz; Tristes trópicos.

Resumen: En los años 1920 y 1930, Mário de Andrade y Lévi-Strauss viajaron por zonas muy aisladas de Brasil. Fueron por lo tanto viajeros y aprendices de un cierto Brasil profundo que después ellos se propusieron difundir y preservar. Este trabajo identifica puntos de convergencia entre los informes del recorrido que se reunieron en $O$ turista aprendiz (primera publicación 1976) y Tristes trópicos (1955) y compara aspectos de la cultura brasileña, mediante la observación de cada uno de los autores. Su interés por el arte popular y las culturas de los pueblos indígenas, con una mirada antropológica, son elementos básicos de ambos libros. Aunque los puntos de partida de

\footnotetext{
${ }^{1}$ Este texto é parte da pesquisa relacionada ao projeto de pós-doutorado em andamento “Os relatos de viagem de Mário de Andrade e Claude Lévi-Strauss" desenvolvido no DLCV, FFLCH, da USP.

2 Professora associada no Departamento de Linguística, Letras Clássicas e Vernáculas da Universidade Federal do Paraná (UFPR). Pós-doutorado em andamento na Faculdade de Filosofia, Letras e Ciências Humanas da Universidade de São Paulo (FFLCH/USP).
} 
los autores fuesen diferentes, tanto geográfica como ideológicamente, la perspectiva antietnocêntrica llama la atención en ambas obras.

Palabras clave: Literatura de viaje; $O$ turista aprendiz; Tristes trópicos.

\section{INTRODUÇÃO}

Tanto Mário de Andrade como Lévi-Strauss percorreram áreas pouco ou nada urbanizadas do Brasil nas décadas de 1920 e 1930. Seus relatos, reunidos respectivamente em $O$ turista aprendiz (primeira publicação, 1976) e Tristes trópicos (1955), mostram lugares e culturas pouco conhecidos mesmo para os brasileiros. As duas obras reúnem grande quantidade de observações de caráter antropológico em confluência com a escrita criativa. A primeira aproximação se dá pelo próprio gênero textual, a literatura de viagem, cujo estudo convida às avaliações feitas por comparação.

O que, na modernidade, é atraso? O que, no Brasil-República, era ainda BrasilColônia? É certo que as viagens favorecem esse tipo de indagação. Às vezes, favorecem igualmente as respostas; outras vezes, as perguntas ficam pairando no ar por longos anos. São dúvidas que a literatura propõe, mas cujo campo privilegiado de investigação são as ciências sociais. Nesse sentido, Octavio Ianni escreveu:

Não é necessário ser exaustivo sobre a presença direta e indireta da viagem no pensamento de muitos cientistas sociais. Muito do que tem sido a força e a originalidade desse pensamento tem por base os dilemas que se colocam e os horizontes que se abrem com as comparações, possibilitando confrontos e contrapontos.

Sob vários aspectos, a comparação revela-se um experimento indireto, mental ou imaginário. O contraponto de situações, ações, relações, processos e estruturas permite sublinhar condições e tendências, estilizar realidades e possibilidades, desvendar nexos e tensões, perceber dimensões recônditas, escondidas nas configurações e nos movimentos da realidade. (IANNI, 2000, p. 16)

Por outro lado, "literatura de viagem" é uma categoria excessivamente ampla, de caracterização imprecisa. Mais que o gênero textual, este artigo prioriza o contexto em que surgiram as obras e a relação delas com o cenário do pensamento antropológico em que foram produzidas.

Dentre os elementos comuns a $O$ turista aprendiz e a Tristes trópicos, merecem destaque as reflexões sobre a grandeza e as misérias de um país ainda por descobrir, o interesse por manifestações culturais variadas, muitas delas na iminência de se 
extinguirem, e a consciência dos autores de que aquelas experiências, por mais ricas que tivessem sido, foram apenas como que o estopim do desejo de planejar alguma outra tarefa muito mais ampla, para a qual a totalidade de suas vidas e a abrangência notável de seus escritos viriam a se mostrar insuficientes.

Mário, que conheceu a Amazônia em 1927 e o Nordeste brasileiro em 1928, já era ao tempo dessas viagens um escritor relativamente famoso, líder do modernismo, e tencionava descobrir e divulgar "outros brasis". Conceitos como o de “desgeografização", concebido para justificar as peripécias de Macunaíma por todo o território nacional, reforçam o aspecto programático das viagens reais, também revelado em cartas e entrevistas de Mário. Foram percursos planejados por longo tempo, em datas que permitissem assistir a determinadas festas populares e conhecer interlocutores da intelectualidade local.

No âmbito da discussão sobre o regionalismo ou o universalismo das manifestações artísticas, Mário incorporou de forma bastante complexa as preocupações nacionalistas. Lembremos que as conquistas iniciais do movimento modernista, voltadas para a dinamização de linguagem que o convívio com as vanguardas europeias rendera, foram sucedidas pela virada nacionalista. Em meados da década de 1920 já seria injusto acusar a primeira geração modernista por excessos de europeização, como fez a certa altura Gilberto Freyre, pois o nacionalismo já se impusera, para o bem e para o mal. Em sua segunda viagem longa, Mário falaria da dura realidade da região visitada de maneira similar àquela dos romances de 30, como já observou Telê Porto Ancona Lopez: "Ao ultrapassar o nacionalismo do decênio de 1920, o diário da segunda viagem de Mário de Andrade aproxima-se do nosso romance na década seguinte, pela abordagem crua da realidade nordestina" (LOPEZ, 2012) ${ }^{3}$.

Pensemos que as viagens ao Brasil relatadas em Tristes trópicos aconteceram uma década depois, entre 1936 e 1938. Claude Lévi-Strauss era então um antropólogo em início de carreira que, nos intervalos de suas aulas na USP ou das pesquisas ligadas ao Museu do Homem, em Paris, visitou aldeias indígenas pouco conhecidas, reunindo material para sua tese de doutorado.

Se o Brasil e a brasilidade estavam no epicentro das preocupações de Mário de Andrade, isso não é verdade em relação a Lévi-Strauss. Nem a brasilidade nem alguma outra preocupação de caráter nacionalista moveram o pesquisador francês. Sua tarefa

\footnotetext{
${ }^{3}$ Descrição de disciplina ministrada no Instituto de Estudos Brasileiros em 2012. Disponível em http://www.ieb.usp.br/curso/ieb5024-o-turista-aprendiz-ii-de-um-diario-de-viagem.
} 
futura envolveria, isto sim, a proposição de um método de estudo que viabilizasse comparar diferentes culturas de forma mais apropriada do que vinha sendo feito pelas ciências sociais da época. Lévi-Strauss começou a organizar seu instrumental teórico e a documentação que o levariam a traçar as bases do Estruturalismo no mesmo período em que se dedicou à escrita de Tristes trópicos, em meados da década de 1950.

Enquanto viajavam, nenhum dos dois poderia vislumbrar a importância das viagens para suas carreiras futuras. No momento da escrita, essa consciência se ampliara um pouco mais. No caso de Lévi-Strauss, quase todo o relato de viagem foi escrito na década de 1950; no de Mário, houve bastante trabalho de organização de originais para uma primeira versão de $O$ turista aprendiz em livro, trabalho esse que foi interrompido pela morte precoce do autor em 1945.

Mário de Andrade, produzindo em um país periférico e desejando contribuir para a inserção do Brasil noutro patamar, propôs-se a documentar manifestações artísticas e folclóricas para que os pesquisadores de sua época e do futuro tivessem material à disposição. Mário não se considerava cientista e abominava a ideia de empregar tempo excessivo na compreensão de detalhes. Mas percebia que era urgente iniciar pesquisas sérias e fundamentadas da riqueza cultural brasileira.

O autor de Ensaio sobre a música brasileira (1925) num primeiro momento priorizou tudo que estivesse relacionado a ritmos e danças folclóricas, sem descuidar também do conhecimento dos mitos, tão presentes na redação de Macunaíma. Em $O$ turista aprendiz, escreveu:

Já afirmei que não sou folclorista. O folclore hoje é uma ciência, dizem... Me interesso pela ciência porém não tenho capacidade pra ser cientista. Minha intenção é fornecer documentação pra músico e não, passar vinte anos escrevendo três volumes sobre a expressão fisionômica do lagarto... (ANDRADE, 1983, p. 232)

Antropologia, etnologia e etnografia não eram ainda campos do conhecimento muito bem delimitados, e a distinção entre esses campos e o folclore apenas se iniciava. Os anos 1920 e 1930 foram essenciais para a constituição da Antropologia enquanto ciência. O próprio Lévi-Strauss, cuja formação incluiu estudos de Filosofia e Geologia, além de leituras do marxismo e da psicanálise, também não se via como antropólogo até sua vinda ao Brasil. No capítulo 6 de Tristes trópicos, intitulado "Como se faz um etnógrafo", ele atribui a uma série de acasos sua aproximação a um ramo da ciência que conciliou dentro dele diversos interesses: "A etnografia proporciona-me uma satisfação intelectual: como história que une por suas duas extremidades a do mundo e a minha, 
ela desvenda ao mesmo tempo a razão comum de ambas." (LÉVI-STRAUSS, 2009, p. 56) O autor via a Antropologia como uma ciência menos abstrata que a Filosofia e menos física que a Geologia, e nesses pressupostos encontrou motivação para empenhar-se numa metodologia que atingiu centralidade no pensamento social da segunda metade do século XX.

A fortuna crítica de Tristes trópicos aponta o livro como exemplo ímpar na vasta produção de seu autor, tanto por seu gênero textual (a literatura de viagem) ter sido pouco frequentado pelo autor, como pelo ensaísmo autobiográfico. No livro ficamos sabendo, por exemplo, de sua passagem pelos Estados Unidos durante a II Guerra Mundial, como judeu exilado em Nova Iorque. Nesse país Lévi-Strauss conheceu Roman Jakobson e se encantou pelos métodos de análise que renovavam os estudos linguísticos, outra área da ciência que se expandia notavelmente. Aproximando a Linguística às ciências sociais, formulou seu sofisticado método estruturalista de interpretação, em princípio aplicado à compreensão de mitos de culturas indígenas geograficamente distantes, que ele percebeu apresentarem muitos pontos em comum.

Ao longo de mais de sessenta anos de produção intensa, Lévi-Strauss escreveu, por exemplo, os quatro portentosos volumes das Mitológicas ( $O$ cru e o cozido, Do mel às cinzas, $O$ homem nu e $A$ origem dos modos à mesa), que divulgaram cursos ministrados na década de 60 em Paris. Dentre os mitos analisados, os da etnia bororo foram revisitados constantemente, assim como os de outras tribos indígenas brasileiras.

Retornemos a meados da década de 1930, quando os dois intelectuais se conheceram e chegaram a atuar conjuntamente. Claude Lévi-Strauss era o francês que atuava em missão de colaboração científica com um país que buscava superar o subdesenvolvimento. Nessa condição, atuou na Universidade de São Paulo como docente, alternando períodos letivos e expedições etnográficas. Mário de Andrade era o brasileiro que, à frente das iniciativas mais profícuas do movimento modernista, engajava-se na então incipiente área das políticas culturais, chefiando o Departamento de Cultura de São Paulo.

Num período em que conceitos e instituições como "patrimônio imaterial", “etnomusicografia”, e mesmo o IPHAN (Instituto do Patrimônio Histórico e Artístico Nacional) ainda não existiam, Mário de Andrade, insatisfeito com a parca atuação dos 
órgãos públicos, e sem abandonar a criação literária e o papel de fomentador das novas gerações de escritores, foi também um político cultural "avant la lettre". 4

O site do IPHAN informa, a respeito da origem desse órgão:

A criação do organismo federal de proteção ao patrimônio, ao final dos anos 30, foi confiada a intelectuais e artistas brasileiros ligados ao movimento modernista. Era o início do despertar de uma vontade que datava do século XVII em proteger os monumentos históricos (http://portal.iphan.gov.br, 2013).

Não ignoramos que mudou muito, e muito rapidamente, a compreensão do que seja preservar o patrimônio cultural ou algum povo indígena. Por outro lado, como este artigo propõe aproximações entre duas obras bastante complexas e distintas entre si, importa marcar, para além dessas diferenças, o pioneirismo dos enfoques de cada um dos dois autores estudados no tocante à preservação de manifestações culturais ameaçadas pelos avanços da modernidade.

\section{O ENCONTRO ENTRE MÁRIO DE ANDRADE E CLAUdE LÉVI- STRAUSS}

Por sua formação e pelo lugar social que ocupava, se poderia esperar de LéviStrauss escritos de posição preponderantemente eurocêntrica. Tristes trópicos mostrouo, ao contrário, como alguém que, além de questionar profundamente o racismo, valorizava a capacidade criadora dos chamados povos primitivos com base em critérios muito particulares, pelos quais aproximava a lógica do pensamento dos indígenas à lógica do pensamento dos povos ditos civilizados. Esse tema foi bastante desenvolvido em O pensamento selvagem, obra lançada em 1962 e que teve enorme repercussão.

Mário, por sua vez, buscou em autores de uma geração anterior, como James Frazer, Tylor e Lévy-Bruhl, o esclarecimento dos conceitos de mentalidade primitiva e pensamento pré-lógico. Segundo a antropóloga Elizabeth Travassos, com base nessas leituras Mário de Andrade teria oscilado entre duas visões:

A primeira entende mentalidade primitiva como sendo a dos povos primitivos (e do povo) - grupos sociais incivilizados e menos civilizados -, eivada de elementos não-racionais. A segunda concebe a mentalidade primitiva como uma camada ou aspecto primitivo da mente, universal, encontrável em todos os homens. (TRAVASSOS, 2002, p. 105)

\footnotetext{
${ }^{4}$ A esse respeito, cf. os artigos "Mário e o Patrimônio um anteprojeto ainda atual, de Fernanda F. da Silva (in Revista do Patrimônio Histórico Artístico Nacional, Brasília, n. 30, 2002. pp. 128-137) e

"Mário de Andrade: mais que um turista aprendiz, um político cultural", de Salete P. M. Sirino (2012). Disponível em http://www.fecilcam.br/educacaoelinguagens/documentos/v1n1/202-211.pdf.
} 
A segunda concepção descrita por Travassos se aproxima bastante daquela formulada em $O$ pensamento selvagem, onde se defende a ideia de que o pensamento "em estado selvagem" tem a mesma natureza do pensamento dito civilizado.

Fica no campo das suposições imaginar os rumos do pensamento do Mário de Andrade antropólogo caso ele tivesse sobrevivido para ler Tristes trópicos e o restante da produção de Lévi-Strauss e de seus contemporâneos. Cerca de vinte anos mais jovem que Mário, Claude Lévi-Strauss não chegou a ser um interlocutor frequente para as inquietudes do criador de Macunaíma no curto período em que conviveram. De toda forma, esse convívio é de grande interesse histórico e pouco mencionado na bibliografia da área de estudos literários.

Escritos de natureza biográfica e depoimentos pessoais, dentre eles entrevistas de Antonio Candido, mostram Lévi-Strauss na época das viagens ao Brasil como uma pessoa introvertida, menos popular no meio acadêmico uspiano do que alguns de seus colegas, porém sempre muito respeitado por seus conhecimentos. Alguns trabalhos acadêmicos da área de Antropologia se debruçaram sobre a importância desse período para a formação de Lévi-Strauss. Destacam-se os estudos de Fernanda Peixoto e a dissertação defendida em 2010 por uma de suas orientandas, Luisa Valentini. Um laboratório de antropologia: o encontro entre Mário de Andrade, Dina Dreyfus e Claude Lévi-Strauss (1935-1938) apresenta em detalhes as ações conjuntas dos três autores citados no título.

Enquanto esteve no Brasil, Dina Dreyfus era casada com Claude e assinava Dinah Lévi-Strauss. Foi com ela, também professora da missão francesa no período da fundação da USP, que Mário de Andrade aprendeu o que havia de mais avançado na etnografia. Mário e Dinah mantiveram um diálogo intenso em que discutiram, por exemplo, as diferenças entre brasileiros e europeus. Desse diálogo dependeu a criação da Sociedade de Etnografia e Folclore em 1937.

Vítima de uma grave doença dos olhos contraída durante uma expedição sobre a qual nos deteremos em seguida, Dinah retornou à França enquanto Claude e sua equipe continuavam em contato com os nambiquara. Nesse período, ela e Mário trocaram cartas sobre as quais já se disse terem sido uma das causas para a separação do casal Lévi-Strauss.

Mário e Claude chegaram a fazer juntos algumas excursões pelos arredores da capital paulista para assistir e documentar festas populares, atividade referida em Tristes trópicos como "etnografia de domingo": 
Podia-se observar e registrar um folclore rústico: festas de maio, quando as aldeias enfeitavam-se de palmas verdes, combates comemorativos fiéis à tradição portuguesa entre 'mouros' e 'cristãos', procissão da 'nau catarineta', navio de papelão armado com velas de papel, romaria a distantes paróquias protetoras dos leprosos onde, entre os eflúvios devassos da 'pinga'(...) bardos mestiços, de botas, vestidos de ouropéis e fantasticamente embriagados, provocavam-se ao som do tambor para duelos de cantigas satíricas. Havia também as crendices e as superstições cujo mapa era interessante fazer: cura do terçol pela fricção de um anel de ouro; repartição de todos os alimentos em dois grupos incompatíveis: 'comida quente, comida fria'. E outras associações maléficas: peixe e carne, manga com bebida alcoólica ou banana com leite. (LÉVI-STRAUSS, 2009, p. 105)

As mesmas excursões não são referidas em $O$ turista aprendiz, que historia as viagens ao Norte e ao Nordeste, mas renderam importantes ensaios de Mário de Andrade, como "O samba rural paulista", do livro Aspectos da música brasileira, e o livro Música de feitiçaria no Brasil.

Em uma dessas ocasiões, Lévi-Strauss tirou uma foto interessante, em que Mário aparece em pé, a céu aberto, com caderninho e lápis em punho, assumindo a típica postura do pesquisador de campo (figura 1). Vale observar que tanto $O$ turista aprendiz como Tristes trópicos trazem como ilustrações muitas fotos feitas pelos próprios autores.

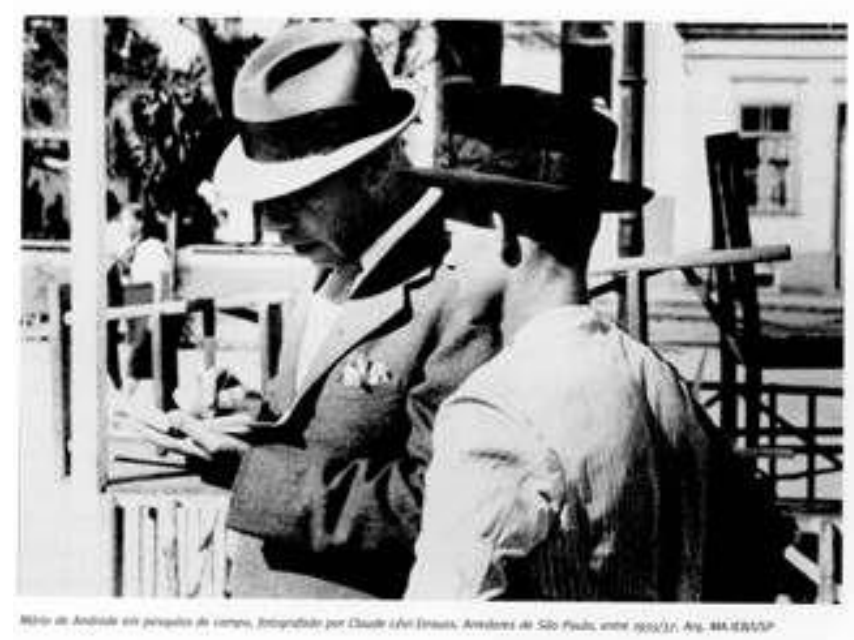

Figura 1 - Foto publicada em SANDRONI, Carlos. Mário, Oneyda, Dina e Claude. Revista do Patrimônio Histórico e Artístico Nacional, Brasília, n. 30, 2002, p. 238.

No plano institucional, o contato entre ambos foi essencial para a viabilização dos trabalhos da equipe francesa no Brasil quando se organizava uma importante expedição para contato com povos indígenas. Salvo engano, a única referência conhecida de Mário de Andrade ao nome de Claude Lévi-Strauss publicada, e que não 
pertence a algum ofício administrativo, se deu, curiosamente, na forma de um desabafo pelo trabalho excessivo que a permanência do antropólogo no Brasil lhe rendeu em certo período. Trata-se de carta a Paulo Duarte, de 3 de abril de 1938, onde se lê:

Não estou fazendo nada a não ser as caceteações que tive com essas viagens etnográficas bestas do Lévi-Strauss e do Oto Leonardos. Estou perfeitamente de acordo que não se faça nada nesta última [....]. Já com o Lévi-Strauss, agora é tarde para voltar atrás. Chega amanhã aqui e conversarei com ele e o atirarei nas suas costas e nas do Sérgio. Se arranjem que preciso de sossego (DUARTE, 1971, p. 157).

"Caceteações" e "viagens bestas" são expressões fortes, que devem ser compreendidas no âmbito da conjuntura política do momento. O desabafo se explica pela posição delicada em que Mário de Andrade se encontrava, pouco tempo antes de perder o cargo de chefia do Departamento de Cultura, no contexto do getulismo, que dificultou ao máximo a efetivação da mais importante excursão comandada por LéviStrauss em nosso país. Mário de Andrade interferiu decisivamente na organização dessa missão etnográfica. É dado histórico que sem essa interferência do diretor do Departamento de Cultura do Município de São Paulo muito provavelmente o projeto teria sido abortado.

Tratava-se da viagem exploratória que ficou conhecida como "expedição à Serra do Norte" que, em 1938, percorreu regiões do Mato Grosso, seguindo pelas imediações das linhas de telégrafo instaladas pelo Marechal Rondon. Dela resultou o estudo aprofundado das tribos nambiquara e tupi-cavaíba apresentado parcialmente na sétima e na oitava partes de Tristes trópicos.

Menos de um mês antes de enviar a referida carta, em 22 de março de 1938, Mário de Andrade comunicara ao Conselho de Fiscalizações das Expedições Artísticas e Científicas no Brasil que o projeto seria dirigido pelo Departamento de Cultura de São Paulo, nos seguintes termos:

Como Diretor do Departamento de Cultura, da Muncipalidade [sic] de S. Paulo, tenho a honra de comunicar a esse Conselho que a expedição etnográfica francesa, á Serra do Norte, chefiada pelo Prof. Claudio Lévi-Strauss, transformou-se em expedição dirigida integralmente por este Departamento de Cultura, e composta de membros brasileiros e franceses (apud. FARIA, p. 16).

Tanto em entrevistas como em depoimentos recolhidos para as obras de memórias Saudades do Brasil e Saudades de São Paulo, Lévi-Strauss manifestou explicitamente o respeito por aquele intelectual que, diferentemente do que preponderava na Pauliceia do período, não fazia pose e não divulgava mais do que 
podia fazer. Por outro lado, o clima geral da intelectualidade paulistana dos anos 1930 foi apresentado em Tristes trópicos com um olhar bastante negativo, que destacou as inconsistências da burguesia endinheirada:

Cabe reconhecer que certos papéis eram representados com um brio extraordinário, graças à combinação entre a fortuna herdada, o charme inato e a matreirice adquirida, que tornavam a frequentação dos salões tão deliciosa e ao mesmo tempo tão decepcionante. Mas a necessidade, que exigia que todos os papéis fossem ocupados para perfazer o microcosmo e representar o grande jogo da civilização, também acarretava alguns paradoxos: que casualmente o comunista fosse o rico herdeiro do feudalismo local, e que uma sociedade muito pretensiosa permitisse, ainda assim, a um de seus membros, mas a um só - já que era preciso ter o poeta de vanguarda -, sair com sua jovem amante em público (LÉVI-STRAUSS, 2009, p. 96).

Nessa possível referência a Oswald de Andrade e outros de sua condição não devemos incluir Mário de Andrade que, além de pertencer a outra camada social, foi sempre apontado por Lévi-Strauss como intelectual laborioso. A título de exemplo, leiase o depoimento seguinte: "Eu conheci bem Mário de Andrade: ele dirigia o Departamento de Cultura da cidade de São Paulo. Fomos muito próximos. Seu romance Macunaíma é um grande livro." (LÉVI-STRAUSS, 2011, p. 44-45). Também é esse o tom em que Lévi-Strauss se refere a Mário em entrevista concedida a Carlos Sandroni em 1993:

(...) mesmo se nós, jovens professores, fomos muito bem acolhidos pelos que eu chamaria de "notáveis" - Júlio de Mesquita Filho, Fernando de Azevedo e outros -, os nossos verdadeiros amigos (aqueles com quem jantávamos, saíamos à noite, fazíamos excursões) eram os do Departamento de Cultura: Mário de Andrade, Sérgio Milliet, Rubens Borba de Moraes... (LÉVI-STRAUSS, apud. SANDRONI, 2002, p. 238).

Esse reconhecimento não deve induzir à ideia de que em Tristes trópicos prevaleça uma visão claramente positiva do Brasil e dos brasileiros, nem o trecho anteriormente citado levar à conclusão contrária, de que tudo é negativo nas referências a paulistanos e brasileiros.

\section{VISÕES DO BRASIL}

Há quem chegue a se irritar com a ironia e os excessos críticos de Lévi-Strauss. É o caso de Walnice Nogueira Galvão ao afirmar que, em Tristes trópicos, “a má vontade para com o Brasil e os brasileiros é incontornável", e que o autor "zomba de 
tudo que lhe passa pela frente, inclusive do nível de colegas e estudantes, de nosso subdesenvolvimento geral" (GALVÃO, 2008, p. 1).

Esse é apenas um dos lados da moeda. Do outro lado, vislumbramos o fascínio de Lévi-Strauss pelos povos indígenas impulsionando-o a superar todo tipo de obstáculo burocrático e de infraestrutura que o Brasil lhe apresentou. Ele não tardaria a exercitar sua autocrítica, reavaliando no próprio relato de viagem seu descrédito inicial no projeto que criou a USP:

Quando cheguei ao Brasil para participar dessa fundação [da USP], julguei - lembro-me ainda - a condição humilhante de meus colegas locais com uma compaixão um pouco arrogante. Ao ver aqueles professores miseravelmente pagos, obrigados, para comer, a fazer obscuros trabalhos, senti o orgulho de pertencer a um país de velha cultura onde o exercício de uma profissão liberal era cercado de garantias e de prestígio. Não desconfiava que, vinte anos depois, meus alunos necessitados de então ocupariam cátedras universitárias, às vezes mais numerosas e melhor equipadas do que as nossas, servidos por bibliotecas como gostaríamos de possuir (LÉVI-STRAUSS, 2009, p. 97).

Retornemos a $O$ turista aprendiz. Como ficou dito, o livro de Mário foi parcialmente escrito durante as viagens e depois o autor se preocupou em estruturá-lo para publicação, porém a morte o alcançou antes de concluída a tarefa. Com base em anotações, esboços e nas crônicas publicadas na imprensa quando da viagem ao Nordeste, uma equipe de pesquisadores do Instituto de Estudos Brasileiros da USP, chefiados pela sempre ativa Telê Porto Ancona Lopez, deu a conhecer em 1976 o volume, tal como vem sendo editado até hoje. Outra equipe, novamente dirigida por Telê Ancona Lopez, trabalha atualmente numa edição comentada cujo lançamento vem sendo postergado há alguns anos. ${ }^{5}$

Entre as viagens de Lévi-Strauss e a redação de seu relato de viagens também se passou um tempo significativo, que permitiu ao autor revisar conceitos e conhecer outras regiões tropicais, como a Índia, o Paquistão e Porto Rico. Ao contrário do que ocorreu com $O$ turista aprendiz, Tristes trópicos foi concebido como obra integral, para fazer parte de uma coleção francesa (Terre Humaine, da editora Plon). Sua publicação alcançou um sucesso surpreendente e projetou o nome de Lévi-Strauss para além do meio acadêmico. Quase um “best-seller", não se pense que essa obra não seja complexa. Acompanhar a cronologia tortuosa e a alternância entre observações diretas e outras altamente filosóficas exige bastante do leitor. Aquele que não tenha nenhuma

\footnotetext{
${ }^{5}$ Informação fornecida pela professora Telê Ancona Lopez, quando lhe apresentei o projeto de pesquisa de que resultou este artigo.
} 
familiaridade com conceitos da Antropologia talvez encontre dificuldade para acompanhar os longos trechos de descrição e interpretação das pinturas corporais geométricas dos cadiueu, por exemplo.

Tristes trópicos não é exclusivamente uma obra de interpretação do Brasil, ou das regiões tropicais. A composição errática, o vai-e-vem das datas e o estilo ensaístico permitem que consideremos a obra como um belo exemplar de bricolage, técnica de composição que Lévi-Strauss estudou. Por motivos distintos, também se poderia considerar $O$ turista aprendiz sob essa designação, já que reúne textos de várias épocas, alterna diário e crônica e ainda inclui considerável quantidade de ficção em meio aos relatos verídicos. A complexidade de ambos os livros torna difícil apresentá-los a contento em poucas linhas, ainda mais quando se tem em vista a perspectiva comparatista. A título de amostragem, passo agora a comparar fragmentos que mostram movimentos similares, ou paralelos, das consciências de Mário e de Lévi-Strauss.

$\mathrm{Na}$ oitava parte de Tristes trópicos, lemos o relato sobre o encontro com os tupicavaíba. O trecho a seguir mostra Lévi-Strauss e quatro companheiros de viagem dirigindo-se a uma aldeia juntamente com Abaitará, um tupi-cavaíba civilizado que lhes serve de guia. No caminho, eles encontram dois indígenas da mesma tribo que ainda viviam afastados da civilização. Um era o chefe da aldeia para onde se dirigiam, o outro seu "lugar-tenente". Abaitará vivia num dos postos da linha telegráfica instalada sob o comando do Marechal Rondon na primeira década do século 20, a estação de telégrafo Pimenta Bueno. O chefe da aldeia e seu auxiliar dirigiam-se para Pimenta Bueno, possivelmente, para preparar a ida definitiva do restante do grupo. A pedido dos etnógrafos, entretanto, eles foram convencidos por Abaitará a adiar aquela visita e retornar à aldeia.

Tomada essa decisão, abandonaram no meio da estrada um gavião, o melhor presente que levavam para os índios civilizados que seriam seus anfitriões. Da maneira como o animal foi deixado, morreria em pouco tempo. Lévi-Strauss indaga: por que algo considerado tão valioso passara de repente a ser insignificante?

O incidente do gavião dava o que pensar. Vários autores antigos relatam que os Tupi criavam gaviões e os alimentavam com macacos, para depená-los periodicamente. Rondon assinalara esse costume entre os Tupi-Cavaíba, e outros observadores, entre certas tribos do Xingu e do Araguaia. Portanto, não era de espantar que um grupo de TupiCavaíba tivesse-o preservado, nem que o gavião, considerado o bem mais precioso deles, fosse levado como presente, se nossos indígenas 
estivessem de fato decididos (como eu começava a desconfiar, e verifiquei em seguida) a deixar definitivamente sua aldeia para aderir à civilização. Mas isso apenas tornava mais incompreensível a decisão de largar o gavião entregue a um lastimável destino. Entretanto, toda a história da colonização, na América do Sul e em outras partes, deve levar em conta essas radicais renúncias aos valores tradicionais, essas desagregações de um gênero de vida em que a perda de certos elementos acarreta a depreciação imediata de todos os outros, fenômeno do qual eu talvez acabasse de observar um típico exemplo (LÉVI-STRAUSS, 2009, p. 326).

A ser verdadeira essa hipótese, a adesão à civilização leva à perda dos costumes numa escala comparável ao efeito dominó. Perde-se um valor, perder-se-ão imediatamente todos os demais. Perante essa constatação, todo o fascínio por conhecer fica impregnado pela culpa e pelos pensamentos negativos em relação à atividade etnográfica. Na sequência, Lévi-Strauss refere-se à adesão ao mundo civilizado com as seguintes palavras: seria a "liquidação melancólica do ativo de uma cultura moribunda".

Em $O$ turista aprendiz que, vale dizer, retrata uma fase muito otimista da vida de Mário de Andrade, predominam o encantamento e o enlevo por presenciar manifestações da cultura popular. Dão exemplo desse estado de espírito as frases seguintes, que se referem a apresentações da Chegança em capitais nordestinas: "Tudo isso enche meu peito que nem posso respirar" (ANDRADE, 1983, p. 219); "E fico maravilhado. Está claro que não se trata duma obra-de-arte perfeita como técnica, porém desde muito já que percebi o ridículo e a vacuidade da perfeição. (...) Meu prazer está compacto como o vento... Os paulistas não conhecem nada disso...” (Id, p. 236); "Me retiro tonto de comoção quando o coro conta que quem venceu definitivamente os mouros foi o duque de Caxias.” (Id., p. 247). São muito citadas as crônicas em que aparece o cantador de cocos Chico Antônio, cujo desempenho artístico impressionou Mário a ponto de ele afirmar: "Não sabe que vale uma dúzia de Carusos." (Id, p. 273). Mas a visita a um engenho promove em Mário a sensação muito desagradável de estar percorrendo algum território ainda sob o jugo da colonização:

Os homens se movendo na entre-sombra malhada de sol, seminus, sempre os chapéus chins; meio que me coloniza a sensação. Não parece mais Brasil... Está com jeito da gente andar turistando pelas África e Ásias do atraso inglês, francês, italiano, não sei quem mais!... Todos os atrasos da conveniência colonial... (ANDRADE, 1983, p. 270).

Ao descrever os mocambos da capital de Pernambuco, a percepção da miséria interrompe o impulso lírico: 
É zona de mocambo, e na água parada, encapuçada de mangue, as casinhas balançam feito luzes de canoas abicadas na praia. São luzes paradas da janelinha de frente, da porta de frente, luzes dum amarelento improvisado, que a água encomprida pra baixo, que nem fachos revirados. A imagem ficou ruim... Não são fachos não; é mas a água doente chupando tudo, chupando a vida da luz, chupando o sangue das gentes habitando aquilo, como quem se aboleta no socavão da morte... pra viver. É triste, bem triste... (ANDRADE, 1983, p. 225$6)$.

Os fragmentos seguintes mostram os autores incomodados pelo fato de viajarem com conforto e sendo detentores de poder, quando confrontam essa condição à das pessoas que conhecem durante os percursos.

O que eu vim fazer aqui!... Hoje o poeta viaja com suas amigas, na Madeira-Mamoré, num limpadinho carro da inspeção, bem sentado em poltronas de cipó-titica, com perdão da palavra, estritamente feitas pelo alemão de Manaus. Vem um garçom fardado lhe trazer um guaraná Simões, de Belém, geladinho, com o gelo mais lindo do mundo que é o de Porto Velho. Hoje o poeta come peru assado feito por um mestre cook de primo cartelllo, que subiu no Vitória, destinado pela Amazon River pra adoçar nossa vida. Às vezes se pára, as paisagens serão codaquizadas, até cinema se traz! pra pegar em nossos orgulhos futuros a palhoça exótica, trançadinha com cuidado e fantasia (ANDRADE, 1983, p. 151-152).

Sentimentos desencontrados tomam conta de Mário ao resumir as atividades do dia 11 de julho de 1927. O prazer de viajar com conforto opõe-se à culpa por ele se sentir aliado à modernidade, que destrói enquanto constrói. As fotos tiradas não seriam capazes de revelar ao mundo os mortos que ficaram pelo caminho, reteriam apenas aspectos exóticos agradáveis ao olhar, como por exemplo, a habilidosa técnica de construção de habitações muito simples. Isso seria suficiente para dar aos habitantes dos centros urbanos a noção de uma viagem exótica pelos confins do país. Mas Mário lamentava a deterioração da região em que se construiu, com o sacrifício das vidas de centenas ou milhares de trabalhadores, a portentosa ferrovia Madeira-Mamoré.

Na sequência do fragmento, o autor nos conta que aquele dia não terminara bem, pois não havia acomodações suficientes no lugar onde a princípio ele dormiria. Ele se deita consternado, tanto pelo desconforto de dormir no trem quanto pelas sensações vivenciadas ao longo do dia, e conclui o texto afirmando: "E durmo no vagão, heroicamente, sem medo das maleitas nem dos mortos, com um gosto raivoso de fraternidade nas mãos" (ANDRADE, 1983, p. 152).

Lévi-Strauss, por sua vez, constrangia-se ao observar a prática de que outros cientistas europeus tanto se orgulhavam, de retornar da África ou da América com relatos muitas vezes mesquinhos tanto do ponto de vista científico como em relação à 
experiência pessoal, que bastavam para lhes render grande reconhecimento social. Ele se perguntava, já acusando: “Quem não enxerga a que ponto essa 'busca do poder' volta a ser valorizada na sociedade francesa contemporânea na forma ingênua da relação entre o público e ‘seus' exploradores?” (LÉVI-STRAUSS, 2009, p. 37).

Para o autor de Tristes trópicos, os viajantes modernos atendiam desejos dos europeus, que já não ansiavam por produtos do tipo pau-brasil ou pimenta, motivações das grandes navegações de séculos anteriores. Seus contemporâneos, e de certa maneira ele também, haviam substituído aqueles desejos pela necessidade de consumir “especiarias morais" que os afastassem do tédio.

Assim como Mário de Andrade, Lévi-Strauss também denunciava que as fotografias, ao passo em que ajudavam a revelar culturas diferentes, serviam também ao exibicionismo daqueles que em pleno século $\mathrm{XX}$ se alimentavam do pouco que ainda restava de exotismo entre povos na iminência da extinção. No trecho seguinte, ele dirige o discurso aos selvagens da floresta amazônica e se refere a um hipotético explorador contemporâneo com o pronome "ele":

Pobre preia caída nas armadilhas da civilização mecânica, selvagens da floresta amazônica, doces e impotentes vítimas, posso resignar-me a compreender o destino que vos aniquila, mas não a ser ludibriado por essa bruxaria mais mesquinha do que a vossa, que brande perante um público ávido álbuns de kodakchromes que substituem as vossas máscaras destruídas? Acredita ele, por esse meio, apropriar-se de vossos encantos? Ainda insatisfeito, e nem sequer consciente de abolir-vos, ele precisa saciar febrilmente com vossas sombras o canibalismo nostálgico de uma história à qual já sucumbistes. (LÉVISTRAUSS, 2009, p. 38)

\section{CONSIDERAÇÕES FINAIS}

No Brasil, poucos foram tão abertamente entusiastas da modernidade como Mário de Andrade. Mas ele não fecharia os olhos às empreitadas demolidoras que, à maneira da construção da Madeira-Mamoré, justificassem as mortes dos operários pela conquista de uma via de comunicação e transporte mais eficiente.

Quanto a Lévi-Strauss, sua visão crítica da modernidade foi gestada na discordância em relação às formas predatórias de exploração dos recursos do planeta.

Esses movimentos das consciências, ou melhor, da má consciência, tanto de Mário como de Lévi-Strauss, aproximam O turista aprendiz e Tristes trópicos no sentido que interessa a este artigo: mostram que eles se deram conta de forma às vezes agônica de que toda descoberta é por si só um princípio de destruição da coisa dada a 
conhecer. Assim, compartilharam um olhar para a diversidade cultural e para o que hoje se denomina sustentabilidade que só viria a prevalecer tempos depois da escrita de seus relatos de viagem.

\section{REFERÊNCIAS}

ANDRADE, Mário de. A situação etnográfica no Brasil. Jornal Sintese. Belo Horizonte, out. 1936. n. 1. ano 1. In. Cantos populares do Brasil: a missão de Mário de Andrade. Catálogo. São Paulo: Centro Cultural São Paulo, s.d., p. 14.

. O turista aprendiz. São Paulo: Duas Cidades, 1983.

. Os cocos. São Paulo: Duas Cidades, 1984.

. Música de feitiçaria no Brasil. Belo Horizonte: Ed. Itatiaia; Brasília: INL, Fundação Nacional Pró-memória, 1983.

Ensaio sobre a música brasileira. Belo Horizonte: Ed. Itatiaia, 2006.

FARIA, Luiz de Castro. Um outro olhar; diário da expedição à Serra do Norte. Rio de Janeiro: Ouro Sobre Azul, 2001.

FRANÇA, Melissa de M. Tristes trópicos, de Claude Lévi-Strauss: entre a etnografia e a literatura. Dissert. de Mestrado. São Paulo: USP, 2006. Disponível em http://www.dominiopublico.gov.br/pesquisa/DetalheObraForm.do? select_action=\&co obra=80419. Acesso em 8 mar. 2013.

GALVÃO, Walnice N. Trópicos não tão tristes. Folha de São Paulo, São Paulo, Mais! 23 nov. 2008. Disponível em http://www1.folha.uol.com.br/fsp/mais/fs2311200810.htm. Acesso em 8 mar. 2013.

IANNI, Octavio. Enigmas da modernidade-mundo. Rio de Janeiro: Civilização Brasileira, 2000.

LÉVI-STRAUSS, Claude. De perto e de longe. São Paulo: Cosac Naify, 2005.

_ L L Longe do Brasil. São Paulo: Editora Unesp, 2011. O pensamento selvagem. Trad. Tânia Pellegrini. Campinas: Papirus, 1989. 2009. . Tristes trópicos. Trad. Rosa Freire D'Aguiar. São Paulo: Companhia das Letras,

LOPEZ, TELÊ A. Homenagem a Dina e Claude Lévi-Strauss: exposição 1937, Paris. Revista do Instituto de Estudos Brasileiros. São Paulo, n. 38, p. 202-220, 1995. . Mário de Andrade: ramais e caminho. São Paulo: Duas Cidades, 1972. 
O Turista Aprendiz II: Dimensões de um Diário de Viagem. São Paulo: USP, 2012. Disponível em http://www.ieb.usp.br/curso/ieb5024-o-turista-aprendiz-ii-de-umdiario-de-viagem. Acesso em 20 abr. 2013.

PEIXOTO, Fernanda. Lévi-Strauss no Brasil: a formação do etnólogo. Rio de Janeiro, Mana, n, 4, v. 1, p. 79-107.

QUEIROZ, Ruben C. de.; NOBRE, Renarde F., orgs. Lévi-Strauss: leituras brasileiras. Belo Horizonte, Editora UFMG, 2008.

TRAVASSOS, Elizabeth. Mário e o folclore. Revista do Patrimônio Histórico Artístico Nacional, Brasília, n. 30, 2002, p. 90-109.

SANDRONI, Carlos. Mário, Oneyda, Dina e Claude. Revista do Patrimônio Histórico e Artístico Nacional, Brasília, n. 30, 2002, p. 233-245.

VALENTINI, Luisa. Um laboratório de antropologia: o encontro entre Mário de Andrade, Dina Dreyfus e Claude Lévi-Strauss (1935-1938). Dissert. de Mestrado. São Paulo: USP, 2010.

WILCKEN, Patrick. Claude Lévi-Strauss; o poeta no laboratório. Trad. Denise Bottmann. Rio de Janeiro: Objetiva, 2011.

Recebido em 05/08/2017.

Aceito em 22/09/2017.

Publicado em 02/01/2018. 